\title{
CHARACTERISATION OF PARTIAL DISCHARGES IN OIL IMPREGNATED PRESSBOARD INSULATION SYSTEMS
}

\author{
Y.P.Nerkar, M.N.Narayanachar and R.S.Nema
}

\begin{abstract}
:
Partial discharge (PD) measurement and interpretation is one of the most useful diagnostic tools for quality assurance testing during the design, manufacture and life assessment of electrical equipments. Pressboard-oil insulation continues to be a major component in the insulation design of EHV transformers. As tests on practical systems are not always feasible due to cost and time factors, model systems tests are gaining importance. In the present work a model insulation system consisting of oil impregnated pressboard with uniform field electrode arrangement has been tested for its behaviour under PDs. It is shown that by defining a modified scale parameter for the Weibull distribution it is possible to take into account the effect of both smaller and larger magnitude PD pulses. The modiffed scale parameter serves as a good index for characterising PD behaviour in oil impregnated pressboard insulation system studied.
\end{abstract}

\section{Introduction}

Pressboard-oil insulation continues to be a major component in the insulation design of EHV transformers. Partial discharges are considered to be hazardous for the satisfactory performance of the insulation system. The gradual deterioration due to PDs can lead to premature failure of the system. Two or mixed parameter Weibull functions are conveniently used to fit the experimental data /1/. Model insulation systems are found to he convenient for the study of PD behaviour $/ 2,3,4,5 /$. In the present work, oil impregnated pressbaord samples have been tested for their PD behaviour at predetermined stress levels. Records of PD pulse distribution patterns are acquired with the help of the multichannel analyser. The data has been analyscd using Weibull statistics. A modified scale parameter of the mixed Weibull distribution is found quite useful for monitoring aging behaviour.

\section{Experimental Procedure}

\subsection{Test Cell}

A pair of $7 \pi / 12$ Rogowski brass clectrodes of $30 \mathrm{~mm}$ overall diameter was used for the study of PD characteristics in a uniform field. A PMMA (Poly Methyl Methaacrylate) coll of volume $130 \mathrm{~mm}$ x $130 \mathrm{~mm}$ x $150 \mathrm{~mm}$ was used for conducting experiments. The pressboard samples were placed betweon electrodes in the PMMA cell filled with transformer oil.

\subsection{Preparation of samples}

Pressboard sheets with nominal thickness of $2.0 \mathrm{~mm}$, mat finished on both sides were used for making samples of $50 \mathrm{~mm}$ diameter. Samples were vacuum dried at a temperature of 100 degree centigrade. Filtered and vacuum treated transformer oil was used for impregnation. The impregnated samples were stored in vacuum tight dissicator containing moisture absorbent.

\subsection{Test Procedure}

The voltage across the samples was raised gradually at an average rate of $2 \mathrm{kV} / \mathrm{s}$ till inception of PD. The inception voltage was noted. PD distributions were acquired using MCA (EG\&G ORTEC), Model 921. Further the voltage was raised to a predetermined stross level as explained in the following section.

\subsection{Criterion for selecting the stress levels}

Initially three samples were tested at a stress level of $12.0 \mathrm{kV} / \mathrm{mm}$. The stress level of $12.0 \mathrm{kV} / \mathrm{mm}$ was close to the inception level $(11.0 \mathrm{kV} / \mathrm{mm}$ average). PD pulse distributions were recorded continuously. It was found that failure of the sample took place only in one case after $230 \mathrm{~min}$ utes of application of overvoltage stress. The 
Table 1

Results of PD tests at different

stress levels

\begin{tabular}{|c|c|c|c|}
\hline $\begin{array}{l}\text { Sample } \\
\text { number }\end{array}$ & $\begin{array}{c}\text { Inception } \\
\text { stress } \\
\text { level } \\
\mathrm{kV} / \mathrm{mm}\end{array}$ & $\begin{array}{c}\text { Applied } \\
\text { stress } \\
\text { level } \\
\mathrm{kV} / \mathrm{mm}\end{array}$ & $\begin{array}{l}\text { Time to } \\
\text { failure } \\
\text { min. }\end{array}$ \\
\hline 1 & 11.60 & 13.0 & 92 \\
\hline 2 & 11.00 & $\overline{13.0}$ & 120 \\
\hline 3 & 11.10 & 13.0 & 67 \\
\hline$\overline{4}$ & 11.00 & 13.0 & 113 \\
\hline 5 & 11.10 & 13.0 & 80 \\
\hline 6 & 10.40 & 13.0 & 92 \\
\hline 7 & 11.00 & $\overline{13.5}$ & $\overline{c 65}$ \\
\hline 8 & 11.80 & 13.5 & 78 \\
\hline$\overline{9}$ & 11.10 & 13.5 & 35 \\
\hline 10 & $12 . \overline{50}$ & 13.5 & 52 \\
\hline 11 & 11.00 & 13.5 & 64 \\
\hline 12 & 11.10 & 13.5 & 206 \\
\hline 13 & 10.50 & 14.0 & 40 \\
\hline 14 & 10.50 & 14.0 & 21 \\
\hline 15 & 12.50 & 14.0 & 60 \\
\hline 16 & 11.00 & & 24 \\
\hline 17 & 11.10 & & 60 \\
\hline 18 & 11.80 & 14.0 & 52 \\
\hline
\end{tabular}

other two tested samples did not fail cven after aging for $\mathbf{2 4}$ hours at which stage the expcriments were terminated. In order to accelerate the aging process due to $\mathrm{PDs}$ an overvoltage stress of $15.0 \mathrm{kV} / \mathrm{mm}$ was tried for two samples. The failure times were 30 minutes and $41 \mathrm{~min}$ utes which were found too short for observing the PD behaviour. Hence an intermediate overvoltage stress levels of $13.0 \mathrm{kV} / \mathrm{mm}, 13.5 \mathrm{kV} / \mathrm{mm}$ and $14.0 \mathrm{kV} / \mathrm{mm}$ were selected for further experimentation. PD pulse distribution patterns were acquired continuously with each record containing pulses for 10 seconds duration.

\section{Analysis of results}

Weibull distribution was used for analysis of PD pulse distribution patterns. The Weibull distribution is given by

$$
F(q)=\mathbf{I}-e^{\left(\frac{-q}{\alpha}\right)^{\beta}}
$$

where $F(q)$ is the cumulative Weibull distribution function. The $a$, known as scale parameter, defines $\mathbf{6 3 . 2 \%}$ probability for the group. The $\beta$, known as shape parameter. $\mathrm{q}$ is the discharge magnitude.

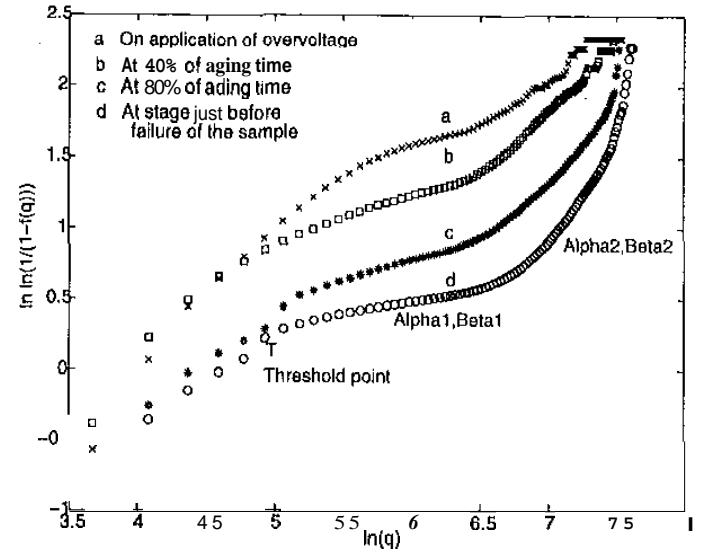

Figure 1: Typical Weibull plots for the sample (no.8) at $13.5 \mathrm{kV} / \mathrm{mm}$

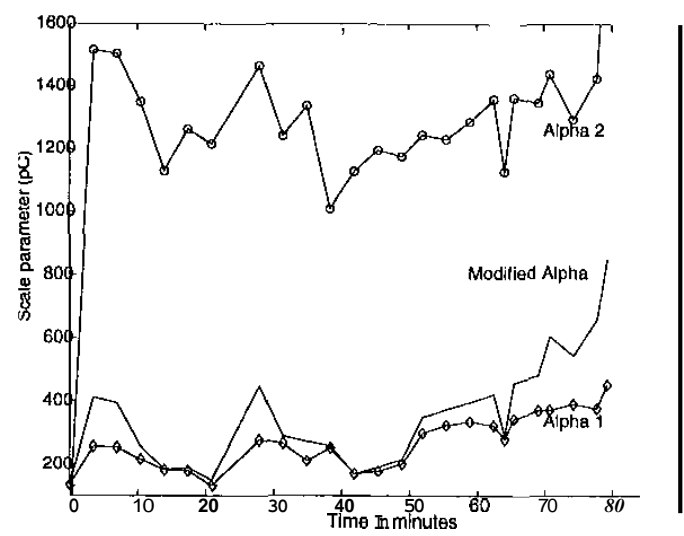

Figure 2: Variation of scale parameters $\alpha_{0}, \alpha_{1}$ and $\alpha_{2}$ with aging time for a typical sample (no.8) at $13.5 \mathrm{kV} / \mathrm{mm}$

A typical Weibull distribution plots are shown in figure 1 . The distribution has been considered in two sections representing $\alpha_{1}, \beta_{1}$ and $\alpha_{2}, \beta_{2}$ parameters. A threshold discharge magnitude was decided and initial portions from Weibull plots were excluded. In order to explain the PD behaviour a modified scale parameter called $\alpha_{0}$ has been defined as

$\alpha_{0}=P_{1} \alpha_{1}+P_{2} \alpha_{2} \quad P_{1}$ is the probability of the first scction of the distribution

$P_{2}$ is the probability of second section of the distribution.

$P_{1}$ and $P_{2}$ are calculated as

$P_{1}=\frac{N_{1}}{\left(N_{1}+N_{2}\right)}$ and $P_{2}=\frac{N_{2}}{\left(N_{1}+N_{2}\right)}$

$N_{1}=$ total number of pulses in scction 1 and

$N_{2}=$ total number of pulses in section 2 . 


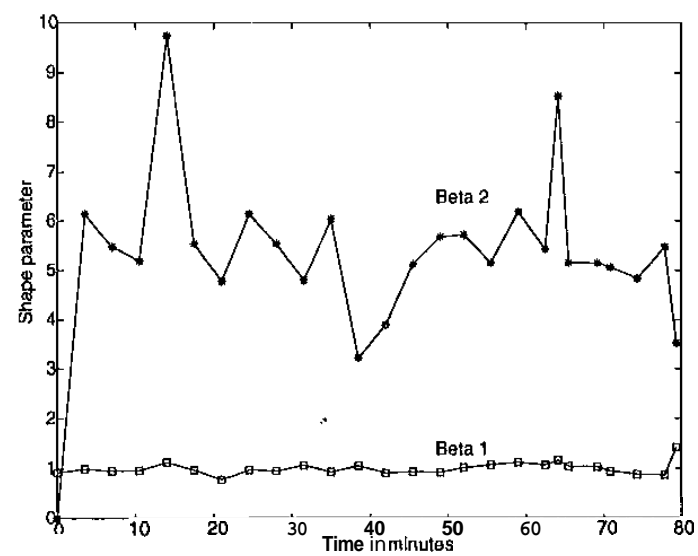

Figure 3: Variation of shape parameters $\beta_{1}$ and $\beta_{2}$ with aging time for a typical sample (no.8) at $13.5 \mathrm{kV} / \mathrm{mm}$

\section{Discussion}

Figure 2 shows the variation of modified Weibull scale parameter $\alpha_{0}$ (Modified Alpha), $\alpha_{1}$ (Alpha 1) and $\alpha_{2}$ (Alpha 2) with time. It is seen that the transition just before the failure of the sample is indicated by the steep increase in the value of the modified scale parameter $\alpha_{0}$. Hence the modified scale parameter $\alpha_{0}$ can be considered as a better indicator of aging due to partial discharges as compared to $\alpha_{2}$, the scale parameter of the higher magnitude discharge pulses only. Figure 3 shows the variation of Weibull shape parameters $p \sim$ and $p \sim$ with time. A modified shape parameter $\beta_{0}$ has not been defined in view of the fact that the large value of $\beta_{2}$ (in the range from 3 to 6 ) of the larger magnitude pulses is a better indicator of the aging rate than the value of $\beta_{1}$ (in the range from 1 to 2 ) given for the smaller magnitude discharge pulses.

The variation in the modified scale parameter $\alpha_{0}$ and shape parameter $\beta_{2}$ for all the system tested at different stress levels are shown in figures 4 to 9 . It may he seen from figures $\mathbf{4 , 6}$ and 8 that initial $\alpha_{0}$ is significantly higher ( $\gg \mathbf{5 0 0}$ ) for the samples at $14 \mathrm{kV} / \mathrm{mm}$. But at the end of aging period, just before the failure of the samples, the values of $\alpha_{0}$ are in the range (1000 to $1200 \mathrm{pC}$ ) for all the stress levels. As shown in figures 5, 7 and $\mathbf{9}$, the range of the $\beta_{2}$ values are 3.2- 5.5 at $13.0 \mathrm{kV} / \mathrm{mm}, 3.5-6.5$ at $13.5 \mathrm{kV} / \mathrm{mm}$ and $4.6-6.5$ at $14.0 \mathrm{kV} / \mathrm{mm}$ indicating a gradual increase in the rate of deterioration of the samples with increase in stress levels. This fact is also reflected in the time to failure (Table $\mathbf{1}$ ).

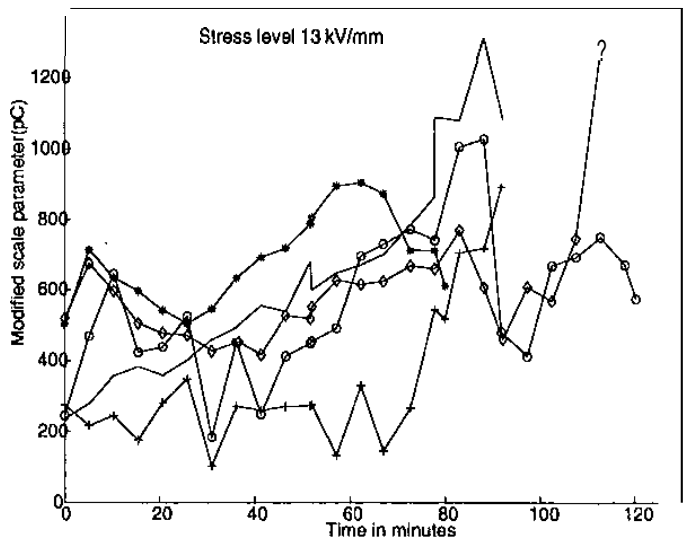

Figure 4: Variation of modified scale parameter $\alpha_{0}$ with aging time at $13.0 \mathrm{kV} / \mathrm{mm}$ for all the samples

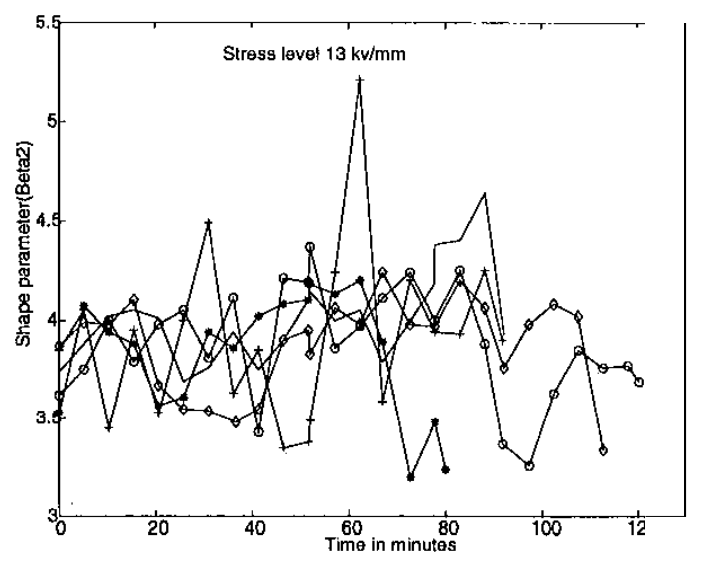

Figure 5: Variation of shape parameter $\beta_{2}$ with aging time at $13.0 \mathrm{kV} / \mathrm{mm}$ for all the samples

\section{Conclusions}

It is shown that by defining a modified Weibull scale parameter the PD behaviour of pressboard insulation system can be studied more effectively than by just considering two modes of the distrbutions. 


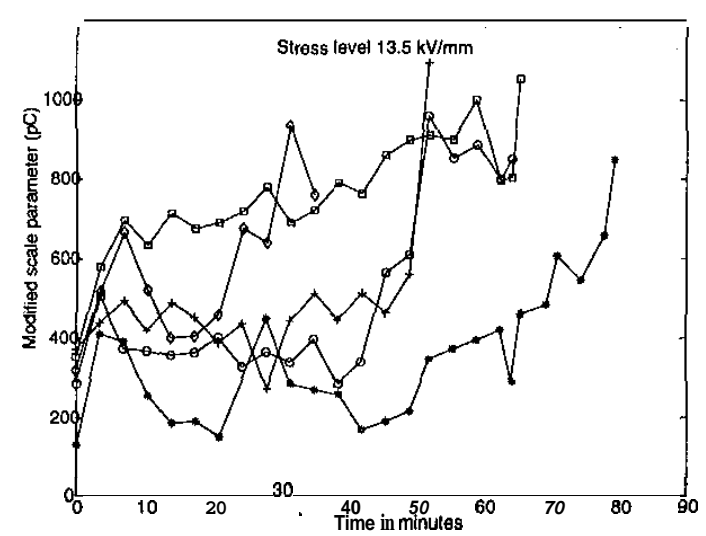

Figure 6 Variation of modified scale parameter $\alpha_{0}$ with aging time at $13.5 \mathrm{kV} / \mathrm{mm}$ for all the samples

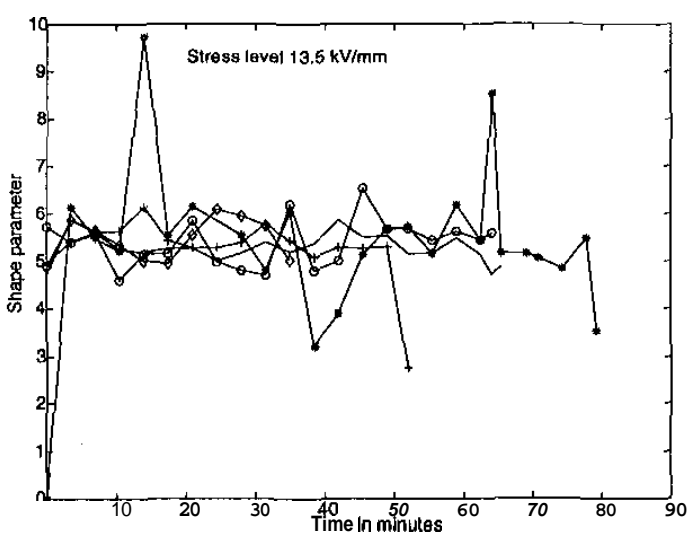

Figure 7: Variation of shape parameter $\beta_{2}$ with aging time at $13.5 \mathrm{kV} / \mathrm{mm}$ for all the samples

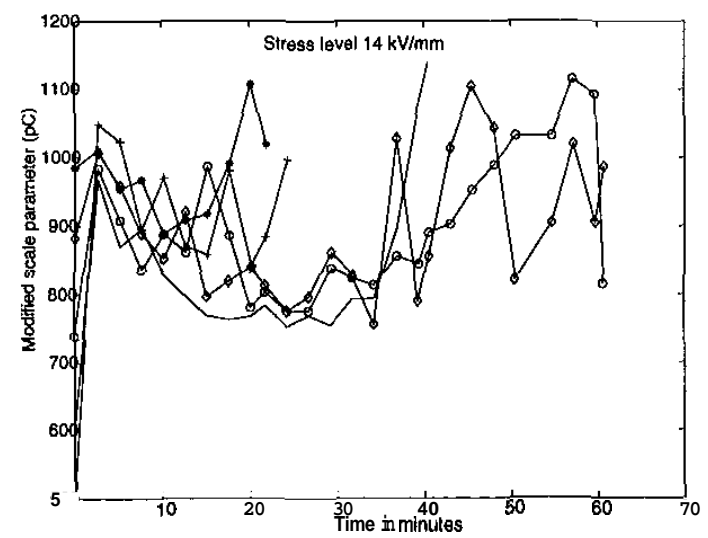

Figure 8: Variation of modified scale parameter $\alpha_{0}$ with aging time at $14.0 \mathrm{kV} / \mathrm{mm}$ for all the samples

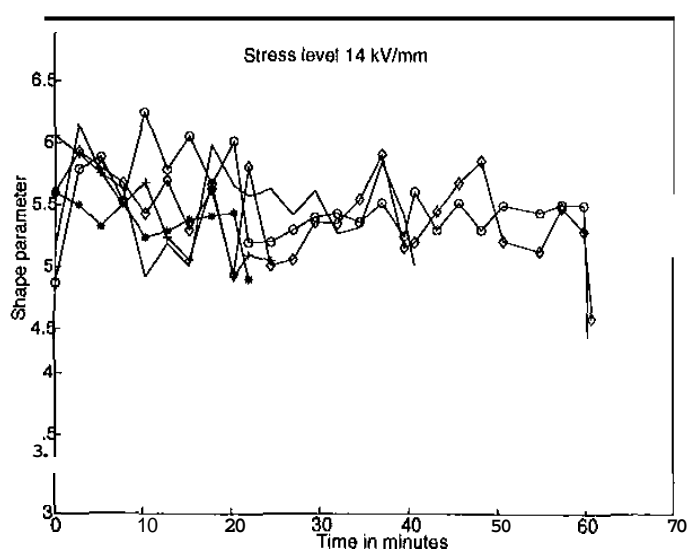

Figure 9: Variation of shape parameter $\beta_{2}$ with aging time at $14.0 \mathrm{kV} / \mathrm{mm}$ for all the samples

\section{References}

/1/ A.Contin,E.Gulski,M.Cacciari and G.C.Montanari "A Weibull approach to the investigation of partial discharges in aged insulation' system", Conference record of the IEEE International Symposium on Electrical Insulation, Montreal, Quebec, Canada, June 16-19,1996,pp. 416-419.

/2/ Palmer S and Sharpely W.A. "Electric strength of transformer insulation", IEE Proc., Vol.116, No.12, December 1969, pp.2029-2038.

13/ Mohsin M.M., M.N.Narayanachar and R.S.Nema "A study of partial discharge characteristics in oil impregnated pressboard insulation", Conference record of the IEEE International Symposium on Electrical Insulation, Montreal, Quebec, Canada, June 1619,1996, pp.79-82.

/4/ K.Raja, M.N.Narayanachar and R.S.Nema "A study of phase angle distribution of partial discharges in oil pressboard insulation system", Conference record of the IEEE International Symposium on Electrical Insulation, Montreal, Quebec, Canada, June 1619,1996, pp.75-78.

/5/ Karlernst Giese "Electrical strength of presshoard and components for transformer insulations" IEEE Electrical Insulation Magarine, Vol 12,No.1, January-February, 1996, pp.29-33. 